\title{
Uma análise sobre os primeiros passos do Grupo de Estudos sobre Meios Autocompositivos
}

\author{
Um analisis sobre los primeiros passos del Grupo de Estudios sobre \\ Medios Autocompositivos
}

An analysis of the first steps of the Study Group on Autocompositive Means

\author{
Josué Goulart dos Santos 1 \\ Alessandra Alfaro Bastos ${ }^{2}$ \\ Gessiane Rehbein ${ }^{3}$
}

\begin{abstract}
Resumo
Sustentado na concepção que os meios autocompositivos são formas para o exercício da cidadania, este trabalho propõe apresentar os resultados das atividades em andamento do Grupo de Estudo sobre Meios Autocompositivos (GEMA) vinculado ao Observatório de Direitos Humanos (ODH) de uma Instituição de Educação Superior (IES) pública. Os meios autocompositivos tem sido amplamente discutido, sobretudo após sua popularização entre 1980 e 1990, pois oferta alternativas para responder a um problema que não é recente: a acentuada dificuldade de se comunicar. O ODH visa ampliar o debate sobre o tema à medida que estimula docentes, discentes, técnicos-administrativos da Universidade e a comunidade em geral a tomarem ações, coletivas ou individuais, de cidadania promovendo a cultura dos Direitos Humanos. O GEMA, grupo de pesquisa e extensão, tem por objetivos promover na comunidade de Santa Maria (RS) o ideal de "direitos humanos" como essencial para mudar a situação de desigualdade e intolerância que vigora em muitos níveis da sociedade brasileira, considerando as práticas autocompositivas como formas de enxergar os problemas sociais de forma construtiva, buscando alternativas através do diálogo e do respeito aos Direitos Humanos. Nessa perspectiva, o GEMA realiza atividades de extensão para promoção da paz através de convênio firmado entre a IES, Ministério Público Estadual (MPE) e a Fundação de Atendimento Socioeducativo (FASE), cujos resultados iniciais serão apresentados neste trabalho.
\end{abstract}

Palavras-Chave: Autocomposição de conflitos; Cidadania; Direitos Humanos.

\section{Resumen}

Sostenido en la concepción que los medios autocompositivos son formas para el ejercicio de la ciudadanía, este trabajo propone presentar los resultados de las actividades en curso del Grupo de Estudio sobre Medios Autocompositivos (GEMA) vinculado al Observatorio de Derechos Humanos (ODH) de una Institución de Educación Superior (IES) pública. Los medios autocompositivos han sido ampliamente discutidos, sobre todo después de su popularización entre 1980 y 1990, pues ofrecen alternativas para responder a un problema que no es reciente: la acentuada dificultad para comunicarse. El ODH pretende ampliar el debate sobre el tema a medida que estimula a docentes, discentes, técnicos-administrativos de la Universidad y la comunidad en general a tomar acciones, colectivas o individuales, de ciudadanía promoviendo la cultura de los Derechos Humanos. El GEMA, grupo de investigación y extensión, tiene por objetivos promover en la comunidad de Santa María (RS) el ideal de "derechos humanos" como esencial para cambiar la situación de desigualdad e intolerancia que rige en muchos niveles de la sociedad brasileña, considerando las prácticas autocompositivas como formas de ver los problemas sociales de forma constructiva, buscando alternativas a través del diálogo y del respeto a los derechos

\footnotetext{
${ }^{1}$ Acadêmico de Licenciatura em Ciências Sociais; Universidade Federal de Santa Maria - UFSM; Santa Maria, Rio Grande do Sul, Brasil; goulartche@gmail.com

${ }^{2}$ Mestre em Ciências Sociais; Universidade Federal de Santa Maria - UFSM; Santa Maria, Rio Grande do Sul, Brasil; alebastos@ymail.com

${ }^{3}$ Especialista em Gestão e Organização da Escola; Universidade Federal de Santa Maria - UFSM; Santa Maria, Rio Grande do Sul, Brasil; ane.rb1985@gmail.com
} 
humanos. En esta perspectiva, el GEMA realiza actividades de extensión para la promoción de la paz a través de un convenio firmado entre la IES, el Ministerio Público Estatal (MPE) y la Fundación de Atención Socioeducativa (FASE), cuyos resultados iniciales serán presentados en este trabajo.

Palabras claves: Autocomposición de Conflictos; Ciudadanía; Derechos Humanos.

\begin{abstract}
Based on the concept that the self-help means are forms for the exercise of citizenship, this paper proposes to present the results of the activities of the Study Group on Autocompositive Means (GEMA) linked to the Observatory of Human Rights (ODH) of a Higher Education Institution (IES). The autocompositive means has been widely discussed, especially after its popularization between 1980 and 1990, because it offers alternatives to respond to a problem that is not recent: the marked difficulty of communicating. The goal of ODH is to broaden the debate on the subject as it encourages teachers, students, technicians-administrative of the University and the community in general to take actions, collective or individual, of citizenship promoting the culture of Human Rights. GEMA, a research and extension group, aims to promote in the community of Santa Maria (RS) the ideal of "human rights" as essential to change the situation of inequality and intolerance that prevails in many levels of Brazilian society, considering the practices as constructive ways of looking at social problems, seeking alternatives through dialogue and respect for Human Rights. In this perspective, the GEMA carries out extension activities for peace promotion through an agreement signed between the IES, the State Public Ministry (MPE) and the Foundation for Socio-educational Assistance (FASE), whose initial results will be presented in this work.
\end{abstract}

Keywords: Autocompositive Means; Citizenship; Human Rights.

\title{
1. Introdução
}

O presente trabalho tem por objetivo apresentar os resultados iniciais da atuação de um Projeto de Pesquisa e Extensão em uma unidade de internação de adolescentes em conflito com a lei. O projeto se desenvolve a partir da proposição de fomento à cultura da paz e respeito aos Direitos Humanos através da adoção de meios autocompositivos, em conjunto com o sistema penal de restrição da liberdade. O trabalho desenvolvido pelo projeto de pesquisa e extensão junto aos menores em situação de privação de liberdade ocorre através de círculos de construção de paz, metodologia da Justiça Restaurativa, nos quais são debatidos temas de interesse dos adolescentes, como: drogadição, superação, objetivos de vida. Proporcionando reflexão, crítica e empoderamento em suas ações individuais e coletivas, visando que em seu retorno à sociedade o mesmo disponha de novas lentes para ver o mundo tomando consciência dos resultados de suas práticas. Os direitos humanos são garantias mínimas às quais todos e todas deveriam ter acesso, assegurando a dignidade da pessoa humana. Na efetivação dessas garantias mínimas como saúde, educação e trabalho, os direitos humanos de $2^{\mathrm{a}}$ geração alcançariam a igualdade, pois, haveria uma diminuição dos crimes cometidos, por tratarem-se, em sua maioria, de ofensa à propriedade.

O método retributivo utilizado pelo sistema penal brasileiro vem desde seu princípio reafirmando sua inegável incapacidade de recuperar, reinserir o culpado e tão pouco satisfazer 
as necessidades da vítima, haja vista os índices de reincidência ultrapassarem os $70 \%$ em todo país segundo dados do Departamento Penitenciário Nacional - DEPEN (2017).

Rolim (2008) observa o fato de nações que aumentaram as taxas de encarceramento nos últimos anos, a exemplo a Inglaterra, agora tem a intenção de repensar esse caminho por se tratar de um recurso caro e com pouca eficiência na reinserção.

\footnotetext{
"As prisões podem cumprir um papel importante na punição de infratores e na proteção do público, mas é um recurso muito caro que deve ser empregado com foco nos perigosos e seriamente contumazes infratores. É imperativo que tenhamos um sistema correcional que puna, mas que também reduza as taxas de reincidência através da reabilitação do infrator e de sua reintegração à comunidade." (United Kingdon, 2002 apud Rolim, 2008)
}

Buscando alternativas que venham a compor satisfatoriamente as vítimas bem como alcançar uma maior efetividade das sanções impostas aos infratores da lei penal, surgem alternativas como a teoria da justiça restaurativa.

\section{Da Justiça Restaurativa}

Reformular o atual conceito de justiça buscar a construção de uma sociedade democrática que garanta os direitos humanos e pratique uma cultura de paz, essa é forma de início da Carta de Araçatuba onde constam os princípios norteadores dessa nova modalidade de fazer justiça no Brasil.

No entendimento de Kant de Lima (2004) "a igualdade é a capacidade de prover tratamento igual aos diferentes, universalizando a aplicação da lei às distintas identidades que se especificam no espaço público". Na sociedade brasileira, Kant de Lima (2004), explica ser a desigualdade um princípio organizador, sendo o sistema penal apenas uma de suas dimensões. Assim os ideais de igualdade, diretores da legislação pátria, restam prejudicados pela prática, e esta disparidade é percebida como natural. Com o argumento de defender os cidadãos de bem, o Estado aposta em uma maior repressão a fim de barrar o crescimento da insegurança. Para tanto, conta com a colaboração dos pares dos vigiados convencendo-os que o criminoso é um inimigo de todos, pois este rompeu com o pacto social, lançando seus golpes contra a sociedade que o protege (Foucault, 2005). O estado tem o dever de combatêlo como inimigo, sob pena de deixar vulneráveis os demais cidadãos.

A Justiça Restaurativa (JR) surge como novo paradigma de justiça, cuja principal característica é a busca pela composição das partes, vítima e infrator, com o auxílio de profissionais capacitados para mediação. São os mais importantes atores da construção de 
soluções, uma vez que imparcialmente estimula o diálogo através dos elementos trazidos pelas partes. Sai o juiz, aquele ser distante e acima das partes, para a entrada de psicólogos, assistentes sociais, membros da comunidade para em igualdade de oportunidades exporem seus entendimentos.

Com o atual modelo de justiça criminal, subsiste um enorme contingente de crimes não notificados, a cifra oculta, as vítimas não realizam a notificação à entidade responsável por inúmeros motivos, sendo principal motivo a falta de confiança na polícia judiciária - por medo de represálias ou descrédito na solução. Além destes problemas inerentes ao sistema penal utilizado, cabe lembrar as vultosas quantias de dinheiro público que envolve seu funcionamento. Segundo dados da Secretaria de Segurança Pública do Estado do Rio Grande do $\mathrm{Sul}^{4}$ (2018) o custo de manutenção de um preso é de $\mathrm{R} \$ 570,55$ e de criação de vaga no regime fechado fica entre $R \$ 1.710,00$ a $R \$ 2.090,00$. Nesse cenário a JR propõe uma mudança de paradigma sobre o conceito de justiça, o crime não apenas como fato típico, ilícito e culpável, mas como uma ruptura entre as relações entre agressor, agredido e comunidade. Logo, a procura pela restauração desses laços rompidos com o trauma, oportuniza e encoraja as pessoas envolvidas a dialogarem, passando a justiça a ser avaliada como a capacidade de restabelecer essa relação através do fato do infrator responsabilizar-se pela infração cometida e as necessidades resultantes do delito atendidas de forma satisfatória (Gomes Pinto, 2008).

\section{Da atuação em um Centro de Atendimento Sócioeducativo sem atividade externa}

O Grupo de Estudos Sobre Meio Autocompositivos, através do método de círculos para construção da paz - modalidade da Justiça Restaurativa - partindo do pressuposto de que sistema penal operando sob a forma tradicional traz pouco êxito quanto aos resultados esperados no tocante à reinserção dos internos, logo existe a necessidade de implementação de formas alternativas de justiça.

Nos círculos, a cada um é oportunizado e respeitado o direito de falar e ser ouvido sendo integralmente responsável por sua fala; ocasião em que os sócioeducandos passam a perceber o crime como fato social (instrumento social que determina, por exemplo, a maneira de agir do indivíduo baseado na sua percepção à partir da generalidade social) e que suas ações não são puramente individuais; logo se dispõem a pensar de forma crítica sobre suas

\footnotetext{
${ }^{4}$ SUSEPE - http://www.susepe.rs.gov.br
} 
práticas quando do retorno à sociedade. A metodologia tem proporcionado a mudança de lentes para as ações individuais e coletivas promovendo novas práticas ao deparar-se com conflitos, sobretudo com uma visão mais humanística. As divergências, por exemplo, passam a ser vistas como oportunidades para condutas democráticas cidadãs e o Direito ocupa o papel de facilitador.

O diálogo nos círculos não tem apenas a intenção de responsabilizar, mas de comprometer-se também com o restabelecimento da harmonia e da comunicação. A cada nova oportunidade de se pensar individualmente, mas também em interações sociais, o sujeito diminui o risco de conflitualidades o que diretamente corrobora em hábitos de concordância com os Direitos Humanos.

O processo desenvolve-se de forma totalmente voluntária e informal com a condução de facilitadores que visam apoiar o melhor desenvolvimento da prática restaurativa estimulando a troca de experiências, o cuidado, o acolhimento oferecendo apoio para o bemestar de todos. Nesse sentido a Justiça Restaurativa insere-se tanto nos princípios da Lei n. ${ }^{\circ}$ 12.594/2012, que instituiu o Sistema Nacional de Atendimento Socioeducativo (SINASE) quanto na Proteção Integral prevista na Lei n. ${ }^{\circ}$ 8.069/1990, Estatuto da Criança e Adolescente (ECA).

De Vitto (2005) lembra a imperatividade de decidirmos se queremos uma nação de jaulas ou de cidadãos, as estimativas indicam o aumento do enorme déficit entre o número de vagas existentes no sistema prisional e a quantidade de pessoas presas (o Brasil é o $3^{\circ}$ no mundo em números absolutos de pessoas presas) ${ }^{5}$, a partir disso conclui-se que seria necessária a criação de milhares de vagas para equacionar o problema. Realidade de impossível correção dados os finitos recursos estatais em verdadeiro descompasso com a cada vez maior taxa de encarceramento, enquanto aquelas crescem à uma progressão aritmética esta cresce exponencialmente. Nesse quadro o modelo integrador da justiça restaurativa vem com um ambicioso projeto de reestruturação da reação ao delito ao pugnar essencialmente pela paz social adéqua-se plenamente a um sistema de afirmação e proteção aos direitos humanos, cujo principal objetivo é assegurar o respeito à dignidade da pessoa humana (De Vitto, 2005).

\section{Conclusões}

\footnotetext{
${ }^{5}$ Segundo dados do International Centre for Prison Studies (ICPS) - http://prisonstudies.org/ -, o Brasil fica atrás apenas dos Estados Unidos e da China.
} 
A Justiça Restaurativa muda o foco para os sujeitos dos conflitos. Estes não são mais simples participantes de um processo burocrático, complexo e de difícil compreensão; serão, portanto, agentes protagonistas do processo. Sobretudo porque, em círculos restaurativos, além da exposição dos fatos, as partes assumem a responsabilidade pelas próximas práticas de restauração de forma voluntária e responsável.

No Brasil desde 1984 com a reforma no Código Penal havia a previsão de penas alternativas como: prestação de serviços à comunidade, restrição de direitos, prestação de pena pecuniária dentre outras. Entretanto, através da Lei 9.099/ 95 (Lei dos Juizados Especiais Criminais) positivou-se a possibilidade de práticas de composição entre as partes nos crimes de menor potencial ofensivo além da suspensão condicional do processo. Nunca poderá ir de encontro aos princípios norteadores do ordenamento jurídico, tão pouco decidirse por um ato manifestamente ilegal. Molina (2000 apud Ferrari 2008) ressalta ser o modelo integrador mais exigente com o infrator por exigir não apenas o cumprimento do castigo, mas uma atitude ativa, participante e responsável.

Uma das principais críticas realizadas a essa teoria alega tratar-se de um retrocesso às sociedades primitivas ao utilizar um simulacro de vingança privada como método de solução de controvérsias. Embora este argumento não encontre respaldo, pois, como refere Zehr (2003 apud Gomes Pinto 2005), nem só de práticas bestiais vivia o homem antes do advento da vingança divina e pública, havia práticas comunitárias de justiça, sobretudo entre indígenas e aborígenes, com características restaurativas e com mediação cuja consolidação advinha de séculos. Não se constituindo retorno, mas avanço ao recuperar valores incansavelmente testados cujos resultados eram positivos (Gomes Pinto, 2005).

$\mathrm{Na}$ atuação do grupo junto aos internos foi observado a aproximação dos participantes por meio de suas histórias de vida, trocas sobre situações difíceis em um ambiente de respeito e amorosidade tal como referido por Pranis (2010 apud Vasconcelos 2017), assim apesar de recente as intervenções têm produzido bons resultados a todos participantes, tanto aos internos quanto aos facilitadores ao proporcionar o exercício da empatia e alteridade em cada prática.

\section{Referências}

BRASIL. Departamento Penitenciário Nacional - DEPEN. Levantamento Nacional de Informações Penitenciárias - Junho de 2016. Brasília: Ministério da Justiça e Segurança Pública, 2017. Disponível em < http://depen.gov.br/DEPEN/depen/sisdepen/infopen>. 
Lei n. ${ }^{\circ}$ 8.069/1990. Dispõem sobre o Estatuto da Criança e do Adolescente e dá

outras previdências. Disponível em <http://www.planalto.gov.br/ccivil_03/LEIS/L8069Compilado.htm>

. Lei n. ${ }^{\circ}$ 12.594/2012. Institui o Sistema Nacional de Atendimento Socioeducativo (SINASE). Disponível em <http://www.planalto.gov.br/ccivil_03/_Ato20112014/2012/Lei/L12594.htm>

DE VITTO, Renato Campos Pinto. Justiça Criminal, Justiça Restaurativa e Direitos Humanos. In Justiça Restaurativa. Brasília, DF: Ministério da Justiça e Programa das Nações Unidas para o Desenvolvimento PNUD, 2005.

DURKHEIM, Émile. Da divisão do trabalho social; As regras do método sociológico; O suicídio; As formas elementares da vida religiosa. In Os Pensadores - Émile Durkheim. São Paulo, SP. Abril Cultural, 1978.

FERRARI, Ana Terra Rosa. Justiça Restaurativa: um novo paradigma. Monografia (especialização) - Universidade do Sul de Santa Catarina, Programa de Pós-Graduação telepresencial e virtual em Ciências Penais, MG, 2008. Disponível em:

<http://www.ibjr.justicarestaurativa.nom.br/pdfs/Artigo_AnaTerra.pdf>

FOUCAULT, Michel. Vigiar e Punir: O nascimento da prisão. 31 ed. Petrópolis, RJ: Vozes, 2005.

RIBEIRO, G. L.. A Globalização Popular e o Sistema Mundial Não-hegemônico. Revista Brasileira de Ciências Sociais. v. 25, p. 21-38, 2010.

Velho, Gilberto. Individualismo e cultura: notas para uma antropologia da sociedade contemporânea. Zahar, 2004.

GOMES PINTO, Renato Sócrates. Justiça restaurativa - um novo caminho? In Revista IOB de Direito Penal, vol. 8, n. 47, 2008. Disponível em:

<http://www.ibjr.justicarestaurativa.nom.br/pdfs/des02052008/Justica_umnovocaminho.pdf>

Justiça Restaurativa é possível no Brasil? In Justiça Restaurativa. Brasília, DF: Ministério da Justiça e Programa das Nações Unidas para o Desenvolvimento PNUD, 2005.

KANT DE LIMA, Roberto. Direitos civis e Direitos Humanos: uma tradição judiciária prérepublicana? In São Paulo em Perspectiva. [online]. 2004, vol.18, n.1. 
ROLIM, Marcos. Justiça restaurativa e segurança pública. In Revista IOB de Direito Penal. Disponível em:

<http://www.ibjr.justicarestaurativa.nom.br/pdfs/JRestaurativa_eSegurancaPublica06_08.pdf $>$

BOURDIEU, Pierre. Espaço social e espaço simbólico. In Razões práticas. Sobre a teoria da ação. Campinas, SP: Papirus, 1996.

Sobre o poder simbólico. In O Poder simbólico. Lisboa. Difel; Rio de Janeiro: ertrand do Brasil, 1989.

CALDEIRA, T. P. R.. Cidade de Muros: Crime, Segregação e Cidadania em São Paulo. 1. ed. São Paulo: Editora 34 e Edusp, 2000.

VASCONCELOS, Augusto César Doroteu de. Justiça Restaurativa e Sistema Socioeducativo no município de Santarém/PA. Dissertação (mestrado) - Universidade Federal do Amazonas, Faculdade de Psicologia, Programa de pós-graduação em Psicologia, AM, 2017. 